\title{
An Assessment of Teratology Training Provided by Masters Level Genetic Counseling Programs
}

\author{
Great Lakes Regional Genetics Group Teratogen Subcommittee: Shari \\ R. Baldinger, ${ }^{1}$ Lola P. Cook, ${ }^{2}$ Beatrice N. French, ${ }^{3}$ Joanne M. Haun, ${ }^{4,8}$ \\ Carol J. Ludowese, ${ }^{5}$ Amy K. Stein Schechtman, ${ }^{6}$ and Wendy R. \\ Uhlmann $^{7}$
}

The increasing demand in the clinical genetics setting for information about teratogen exposures has created a need for genetic counselors to have the capabilities to appropriately address patient concerns. In order to assess how training in teratogen counseling is currently being conducted, the GLaRGG Teratogen Subcommittee surveyed all 17 genetic counseling training programs in North America in September 1993. Information was obtained from training programs about coursework, resources, and clinical training. In addition, each training program was asked to provide information about how their teratogen training needs could better be met. While all programs responded that some information in their coursework applicable to teratogen counseling was provided, there was wide variation in the amount of time devoted to this topic. The programs also greatly differed in the provision of clinical training in teratogen counseling. For both coursework and clinical work, genetic counselors were the main trainers in teratogen counseling. In spite of this, fewer

\footnotetext{
${ }^{1}$ Perinatal Center, Abbott-Northwestern Hospital, Minneapolis, Minnesota.

${ }^{2}$ Department of Medical \& Molecular Genetics, Indiana University School of Medicine, Indianapolis, Indiana.

${ }^{3}$ Department of Pediatrics, Medical College of Ohio, Toledo, Ohio.

${ }^{4}$ Wisconsin Clinical Genetics Center, University of Wisconsin, Madison, Wisconsin.

${ }^{5}$ Department of Obstetrics \& Gynecology, Hennepin County Medical Center, Minneapolis, Minnesota.

${ }^{6}$ Section of Reproductive Genetics, Department of Obstetrics \& Gynecology, Northwestern University Medical School, Chicago, Illinois.

${ }^{7}$ Division of Molecular Medicine \& Genetics, University of Michigan, Ann Arbor, Michigan. ${ }^{8}$ Correspondence should be directed to Joanne Haun, 347 Waisman Center, 1500 Highland Avenue, Madison, Wisconsin 53705.
} 
than $25 \%$ of training programs have a defined teratogen clinical rotation. Data from the survey are discussed and recommendations presented.

KEY WORDS: teratology; training; genetic counseling.

\section{INTRODUCTION}

The provision of information about exposures during pregnancy has become an integral part of the practice of genetic counseling. The organization of responses to such inquiries has evolved into the establishment of teratogen information services around the country. Many such services are staffed by genetic counselors. This emphasizes the importance of adequate training of genetic counseling students in the principles of teratology, risk assessment and the provision of appropriate information to inquiring physicians and their patients (Stein et al., 1994). Furthermore, the need for teratogen counseling skills was specified in the Asilomar guidelines (Walker et al., 1990) and in the 1996 criteria for American Board of Medical Genetics and American Board of Genetic Counseling certification (American Board of Medical Genetics, 1994; American Board of Genetic Counseling, 1994).

In an effort to assess the current level of teratogen training in the master's level genetic counseling programs of North America, each program was surveyed by the Great Lakes Regional Genetics Group (GLaRGG) teratogen subcommittee. At the time, there were 17 genetic counseling training programs, 13 of which are associated with a university medical center. A list of training programs surveyed appears in Appendix A.

\section{MATERIALS \& METHODS}

The GLaRGG teratogen subcommittee formulated a questionnaire to assess how genetic counseling students were trained in teratogen counseling. The questionnaire was sent in September 1993 to all 17 master's level genetic counseling training programs in North America and the response rate was $100 \%$. A copy of the survey appears in Appendix B.

\section{RESULTS}

The programs vary in year of inception, the number of students and the length of time teratogen training has been part of the program (Table I). Counseling of patients whose sole indication for genetic counseling was 
Table I. Program Demographics

\begin{tabular}{lccc}
\hline \multicolumn{1}{c}{ Name of program } & $\begin{array}{c}\text { Year program } \\
\text { began }\end{array}$ & $\begin{array}{c}\text { Teratogen } \\
\text { training since: }\end{array}$ & Students/yr \\
\hline Brandeis University & 1992 & 1992 & 7 \\
Howard University & 1980 & 1990 & $4-5$ \\
Indiana University & 1991 & 1992 & $3-4$ \\
McGill University & 1985 & 1985 & $5-7$ \\
Medical College of & 1990 & 1990 & $4-5$ \\
$\quad$ Virginia/Virginia & & & \\
$\quad$ Commonwealth University & 1990 & 1990 & 6 \\
Northwestern University & 1969 & $?$ & 25 \\
Sarah Lawrence & 1973 & 1983 & 8 \\
UC Berkeley & 1973 & 1973 & $4-5$ \\
UC Irvine & 1981 & 1981 & 7 \\
University of Cincinnati & 1973 & 1990 & 7 \\
University of Colorado & 1979 & 1988 & 4 \\
University of Michigan & 1989 & 1989 & $5-6$ \\
University of Minnesota & 1972 & 1985 & $10-15$ \\
University of Pittsburgh & 1985 & 1985 & 6 \\
University of South Carolina & 1988 & 1988 & 3 \\
University of Texas & 1976 & 1984 & $4-5$ \\
University of Wisconsin & & & \\
\hline
\end{tabular}

a teratogen exposure was a component of all 17 programs. While the total number of patients counseled by each student for this indication varied from 2 to 30 , most programs reported an average of ten cases per student. Documentation of teratogen counseling by a student also varied and is summarized in Table II.

Four of the 17 genetic counseling programs had a defined, separate rotation whose sole focus was teratogen counseling. These four programs required that all students complete the teratogen rotation. The duration of the teratogen rotation ranged from 4 to 10 weeks. All programs with a separate teratogen rotation had an established teratogen information service (TIS) on site. Those programs without a separate teratogen rotation

Table II. Documentation Following a Teratogen Exposure Consultation

\begin{tabular}{lrr}
\hline Letter to MD, letter to patient and chart notes & $52 \%$ & $(9 / 17)$ \\
Letter to MD and chart notes & $12 \%$ & $(2 / 17)$ \\
Letter to MD and letter to patient & $6 \%$ & $(1 / 17)$ \\
Letter to patient and chart notes & $6 \%$ & $(1 / 17)$ \\
Letter to MD & $6 \%$ & $(1 / 17)$ \\
Documentation varies within training program & $12 \%$ & $(2 / 17)$ \\
$\quad$ depending on clinic site & & $(1 / 17)$ \\
No indication given about type of documentation & $6 \%$ & $(120)$ \\
\hline
\end{tabular}


indicated that teratogen counseling was part of either a prenatal or general genetics clinic rotation. Most programs indicated that their coursework included some lectures on topics related to teratogen counseling.

Questions about resources available to students for teratogen cases showed that most training programs had a combination of reference books, computer programs, and literature files. Thirteen of the 17 programs (76\%) had four or more reference books available for student use. Sixteen of the 17 programs (94\%) had access to the REPROTOX and/or TERIS computer programs. Other resources available for students included MEDLINE, product manufacturer information, TIS's, and consultants with specific areas of expertise. In addition, a variety of embryology textbooks were used either in coursework or during clinic rotations. Reference books and embryology textbooks cited by training programs are listed in Appendix C.

There was considerable variation in both the amount and the manner in which training on topics relevant to teratogen risk counseling was provided. Table III summarizes this variation. Principles of teratology and principles of embryology were the two topics covered most consistently in a didactic manner by training programs. The degree of coverage ranged from three lectures or less to a formal course. Five of the training programs did not provide training in principles of epidemiology. For those who provided training, all did so in a didactic lecture setting. The majority of programs did not provide training in principles of pharmacology.

Other general training with applicability beyond teratogen risk counseling, such as phone counseling skills, use of resources, and literature critique was different among programs (Table III). All programs provided training in the use of resources, but through a combination of formal lecture and clinical experience. As expected, phone counseling training was

Table III. Coverage of Teratogen Related Topics

\begin{tabular}{lrc}
\hline \multicolumn{1}{c}{ Topic } & \multicolumn{2}{c}{$\begin{array}{c}\text { Programs providing } \\
\text { training }\end{array}$} \\
\hline Principles of teratology & 16 & $(94 \%)$ \\
Principles of embryology & 15 & $(88 \%)$ \\
Principles of epidemiology & 12 & $(70 \%)$ \\
Principles of pharmacology & 8 & $(47 \%)$ \\
Teratogenicity of specific agents & 17 & $(100 \%)$ \\
Occupational exposures & 14 & $(82 \%)$ \\
Recreational drug exposures & 16 & $(94 \%)$ \\
Maternal diseases & 16 & $(94 \%)$ \\
Infectious diseases & 16 & $(94 \%)$ \\
Phone counseling skills & 15 & $(88 \%)$ \\
Use of resources & 17 & $(100 \%)$ \\
Literature critique & 15 & $(88 \%)$ \\
\hline
\end{tabular}


provided through clinical rotation experiences, but only in 12 programs. One program did not provide training in either phone counseling skills or literature critique. However, some of those surveyed indicated that literature critique and phone skills could be addressed in different disciplines. All programs provided training about teratogenicity of specific agents, however, there was limited coverage of occupational exposures.

The majority of instructors involved in student training were genetic counselors. For those programs that use other health professionals, $82 \%$ involved $\mathrm{MD} / \mathrm{PhD}$ geneticists, $29 \%$ had biologists/embryologists, and $53 \%$ used $\mathrm{PhDs}$ from other specialties. A single program involved professionals from seven different disciplines, which in addition to those listed above, included an occupational health specialist, a registered nurse, and a radiation specialist. Each of these professionals provided training through a section of a course and through clinical rotation. Among the programs, the median number of disciplines utilized in providing training was three (range 1-7). Although we attempted to assess the teratology training and continuing education of the instructors, the diversity of response precluded further analysis.

Although all the programs surveyed already provided some training in teratogen counseling, most $(88.2 \%)$ indicated an interest in additional curricular material to incorporate in their program. Only four $(23.5 \%)$ felt they provided good or adequate training, but two of them felt they could benefit from more material.

In answer to questions about content/form of instructional material, all programs desiring materials (15 of 17 ) included a selected series of individual topics or a "menu" approach. This appeared to be the most attractive option for program directors. (Table IV).

A need and desire among genetic counseling training programs to enhance teratology training are indicated by this survey. Only four of the 17 $(23.5 \%)$ respondents had teratology "experts" available to provide training. On the other hand, 13 of 17 had clinical geneticists and 16 of 17 had genetic counselors available to teach prepared curricula.

\section{DISCUSSION}

Training genetic counseling students in the area of teratogen counseling is recognized as an integral part of the curriculum by the 17 graduate programs surveyed. Although it is difficult to clearly define the exact nature and extent of the training provided by each program it is apparent that the training is delivered in a non-uniform manner. Such variation may result in significant differences in the level of expertise achieved by genetic counseling students. It is also clear that available technical and reference 
resources are diverse. The training varies in lecture/course expectations as well as actual counseling experience. Programs with a TIS on site offer the most intensive and complete training.

Furthermore, while programs have a wide variety of professionals who provide teratogen training, genetic counselors often have the primary role of instruction/supervision of the students. This is not surprising, as the majority of teratogen training occurs within the context of a clinical rotation for which genetic counselors are the student supervisors. Thus, the signifi-

Table IV. Type of Course Material Desired by Training Programs

\begin{tabular}{|c|c|c|c|c|}
\hline $\begin{array}{l}\text { Selected } \\
\text { Series of } \\
\text { Lectures } \\
\text { (Menu }\end{array}$ & $\begin{array}{l}\text { One-Three } \\
\text { Day } \\
\text { Intensive } \\
\text { Course }\end{array}$ & $\begin{array}{l}\text { One Week } \\
\text { Course }\end{array}$ & $\begin{array}{l}\text { Half- } \\
\text { Semester } \\
\text { Course }\end{array}$ & $\begin{array}{l}\text { None } \\
\text { Requested } \\
\text { (Adequate } \\
\text { Coverage) }\end{array}$ \\
\hline
\end{tabular}

$\begin{array}{lllll}15 & 6 & 5 & 1 & 2\end{array}$

Type of Course Material Desired

by Programs

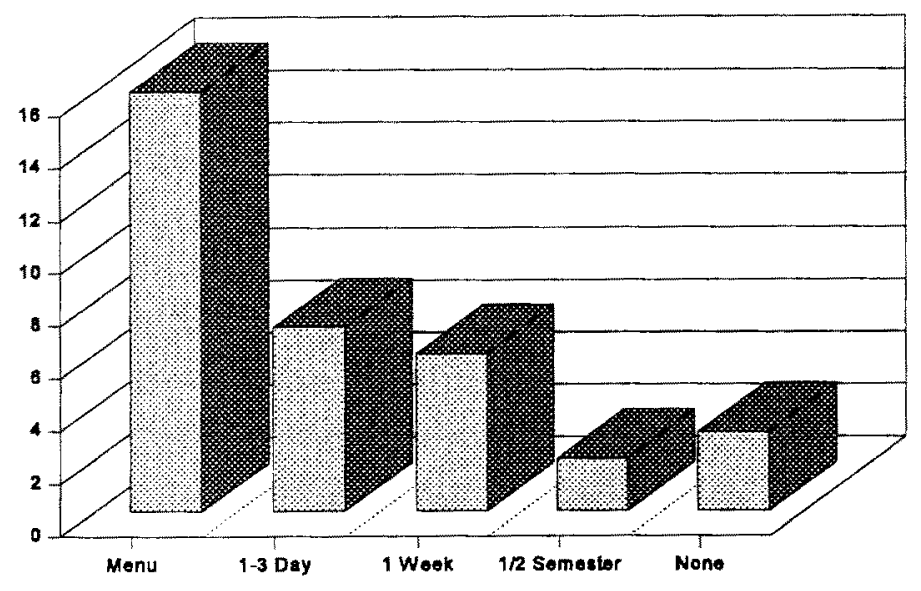


cant variability of teratogen training may also reflect the varied and sporadic training of the genetic counselors themselves.

The majority ( $88 \%$ ) of programs expressed a desire for additional curriculum/training materials; most programs preferred a menu or modular approach because of limited time and lack of human resources. It is suggested that all topics listed in Table III could be part of a modular curriculum, thus allowing programs to be selective about lectures to enhance and supplement what is currently being provided. This material should be updated with advances in the field. In addition, the development of a casebook with teratogen counseling scenarios could be part of this teaching module. Its purpose would be to supplement those programs with a limited amount of clinical experience in different areas of teratogen counseling.

\section{CONCLUSION}

As the field of genetic counseling has expanded, the need for specialized training in teratogen counseling has been recognized. Individual genetic counseling training programs have provided such training. However, the content and scope of training depended on the resources and staff available in each program. If genetic counseling students are to be trained adequately, and in a standardized manner, each training program must have access to comparable resources. We suggest that teratogen training teaching modules be developed to attain a more complete and uniform training process, perhaps create a professional standard for teratogen counseling training, and to fill some of the gaps in current programs (Koren, 1992; CORN committee, 1994). In addition, the establishment of minimum criteria or guidelines for teratogen training may be helpful in the future for evaluation of accredited genetic counseling training programs and for the development of certification standards for genetic counselors.

\section{ACKNOWLEDGMENTS}

The authors especially thank the directors of the Genetics Counseling Training Programs for their time in completing the survey and their $100 \%$ response rate. In addition, the authors would like to thank Renata Laxova, $\mathrm{MD}, \mathrm{PhD}$, Louise Elbaum and Susan Fenton of the Great Lakes Regional Genetics Group for their support and assistance. Supported in part by Project MCJ-551004-04 from the Maternal and Child Health Bureau (Title V, Social Security Act), Health Resources and Services Administration, Department of Health and Human Services. 


\section{REFERENCES}

American Board of Genetic Counseling, Inc. (1994) Bulletin of Information, Descriptions of Examinations. Bethesda, MD.

Council of Regional Networks for Genetic Services (CORN) (1994) Framework for provision of teratology information services, special article. Reprod Toxicol 8(5):439-442.

Koren G (1992) A quality assurance program for teratogen information services. Reprod Toxicol 6(4):293-295.

Stein AK, Fine BA, Pergament E (1994) Training genetic counselors to provide teratogen counseling. I Genet Counsel 3(2):133-140.

Walker AP, Scott JA, Biesecker BB, et al. (1990) Report of the 1989 Asilomar meeting on education in genetic counseling. Am J Hum Genet 46:1223-1230.

\section{APPENDIX A. MASTER'S-LEVEL GENETIC COUNSELING TRAINING PROGRAMS IN NORTH AMERICA IN 1993 (LIST PROVIDED BY THE NATIONAL SOCIETY OF GENETIC COUNSELORS)}

Genetic Counseling Program

University of California at Berkeley

Berkeley, California

Genetic Counseling Program

Univ. of California Irvine Medical Center

Orange, California

University of Colorado Health Sciences Center The Children's Hospital

Denver, Colorado

Howard University College of Medicine

Division of Medical Genetics

Washington, D.C.

Northwestern University Medical School

Graduate Program in Genetic Counseling

Chicago, Illinois

Department of Medical and Molecular Genetics Indiana University Medical Center Indianapolis, Indiana

Genetic Counseling Program

Department of Biology

Brandeis University

Waltham, Massachussets

Genetic Counseling Program

University of Michigan Department of Genetics Ann Arbor, Michigan
Genetic Counseling Program

University of Minnesota

Minneapolis, Minnesota

Human Genetics Program

Sarah Lawrence College

Bronxville, New York

Genetic Counseling Program

Department of Environmental

Health/Kettering Labs University of

Cincinnati Cincinnati, Ohio

Genetic Counseling Program

Department Human Genetics

University of Pittsburgh

Pittsburgh, Pennsylvania

Genetic Counseling Program

University South Carolina School of Medicine Department Obstetrics \& Gynecology Columbia, South Carolina

Genetic Counseling Program

University of Texas-Medical School at Houston Department of Pediatrics

Houston, Texas

Medical College of Virginia

Virginia Commonwealth University

Department Human Genetics

Richmond, Virginia 
Genetic Counseling Program Madison, Wisconsin

University of Wisconsin
Center for Human Genetics

McGill University

Montreal, Quebec

Canada

\section{APPENDIX B. TERATOGEN TRAINING SURVEY, GREAT LAKES REGIONAL GENETICS GROUP, TERATOGEN SUBCOMMITTEE}

\section{A. General Information}

1. Number of students per class in your genetic counseling training program

2. Site:

HMO private hospital/medical facility university medical center private practice (other)

3. Staff involved in training of your genetic counseling students. \# on site \# off site
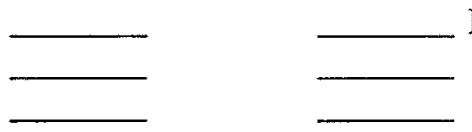
$\mathrm{BC} / \mathrm{BE}$ genetics counselor $\mathrm{MD} / \mathrm{PhD}$ - clinical $\mathrm{MD} / \mathrm{PhD}$ - molecular

4. When was your genetic counseling training program established?

5. Does your clinical genetics program provide teratogen counseling? $\mathrm{Y} \mathrm{N}$ Do you provide counseling: a) by phone b) in clinic c) both Do you have a formal, established Teratogen Information Service? Y N if yes, how many inquiries does the service handle per year?

6. Is teratogen training provided to the genetic counseling students? Y N

Was this part of the training when your program began? $\mathrm{Y} \mathrm{N}$ Is teratogen training required? $\mathrm{Y} \mathrm{N}$

B. Genetic Counseling Training Program Teratogen Training

7. What, if any, embryology text is used as part of your program?

8. What resources do your students have access to regarding teratogens?

Which teratogen database? 
Which texts?

Do you have teratogen literature files?___ How extensive are they?

9. Do your students see patients whose sole reason for a clinic visit is due to a pregnancy exposure? Is this a requirement? $\mathrm{Y} \mathrm{N}$ How many patients of this type are students required to see?

How many patients of this type do students generally see?

10. Are students required to write letters to physicians, patients or to write chart notes regarding exposures?

11. To whom else besides your genetic counseling students is this course/rotation offered?

Comments:

12. Please provide the following information regarding the teratogen training of your genetics counseling training program.

Topic

Principles of teratology

Principles of neurobehavioral teratology

Principles of embryology

Principles of epidemiology

Statistics

Literature critique

Use of resources

Principles of pharmacology

Phone counseling skills

Teratogenicity of specific agents

Occupational exposures

Maternal disease

Infectious diseases

Recreational drug exposures

List

A - formal course
How provided (see list) \# of hours
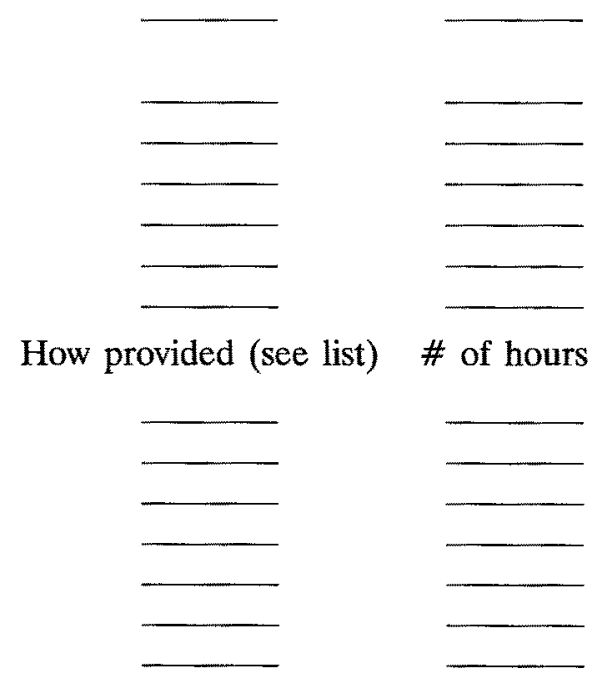
B - incorporated into other courses

C - clinical rotation

$\mathrm{D}$ - assigned reading

E - not provided

F - other

Topic

Who teaches (see list)

Principles of teratology

Principles of neurobehavioral teratology

Principles of embryology

Principles of epidemiology

Statistics

Literature critique

Use of resources

Principles of pharmacology

Phone counseling skills

Teratogenicity of specific agents

Occupational exposures

Maternal disease

Infectious diseases

Recreational drug exposures

List

A - genetic counselor

B - medical geneticist

C - toxicologist

D - pharmacologist

E - embryologist

F - occupational health specialist

$\mathrm{G}$ - developmental biologist

$\mathrm{H}$ - nurse

I - MD

J - other

C. Staff Training

13. If teratogen counseling is provided at your clinical center, what training does the person providing that counseling have?

14. Have the staff had formal training in teratology? $\mathrm{Y} \mathrm{N}$ 
If yes, briefly describe

15. Are staff required to take the Human Teratology course offered by Massachusetts General Hospital and Harvard Medical School? Y N

16. Do the staff participate in continuing education for teratology? $\mathrm{Y} N$ If yes, briefly describe.

17. Are there courses available in your academic community? $\mathrm{Y} N$ Are staff encouraged/required/financially assisted to attend? $\mathrm{Y} \mathrm{N}$

18. Are there "experts" available for consult? Y N

From what specialities?

Are they paid/formally affiliated with your center?

D. Program Needs

19. Would you be interested in curricular material to incorporate teratogen counseling into your program? Y N

If so, which would best suit your needs?

a select series of individual lectures/topics (menu approach) 1-3 day intensive short course one week course one term course

20. Check among the following which personnel could be available for your program/instructors: teratogen counselor embryologist Pharm. D. teratologist interested clinical geneticist

21. If you currently provide teratogen training to genetic counseling students in your training program, would you be willing to provide us with a summary of topics presented and requirements?

\section{APPENDIX C. RESOURCES}

Berkowitz RL, Couston DR, Mochizuki TK (1986) Handbook for Prescribing Medications During Pregnancy (2nd Ed). Boston: Little, Brown and Company. 
Briggs GG, Freeman RK, Yaffe SJ (1994) Drugs in Pregnancy and Lactation (4th Ed). Baltimore: Williams and Wilkins.

Kelley-Buchanan C (1988) Peace of Mind During Pregnancy. New York: Facts on File Publications.

Larsen WJ (1993) Human Embryology. New York: Churchill Livingstone.

Moore KL (1993) The Developing Human (5th Ed). Philadelphia: WB Saunders.

Physicians' Desk Reference (48th Ed) (1994) Montvale: Medical Economics Data Production Company.

Reprotox(1994) Washington, D.C.: Reproductive Toxicology Center.

Sadler TW (1990) Langman's Medical Embryology (6th Ed). Baltimore: Williams and Wilkins.

Schardein JL (1993) Chemically Induced Birth Defects (2nd Ed). New York: Dekker.

Shepard TH (1992) Catalog of Teratogenic Agents (7th Ed). Baltimore: Johns Hopkins University Press.

TERIS, The Teratogen Information System and the On-line Version of Shepard's Catalog of Teratogenic Agents (1994). Seattle: University of Washington. 